\title{
The Unity and Difference of the Speculative and the Historical in Hegel's Concept of Geist
}

\author{
David A. DuQuetTe
}

While Hegel scholars overall have acknowledged that the concept of Geist (Spirit or Mind) is central to Hegel's comprehension of history, there is some degree of controversy among commentators concerning the interpretation of this concept. ${ }^{1}$ The difficulty arises in large part from certain ambiguities that seem built into the concept, in addition to the fact that the complexity of Hegelian concepts and the language employed to express them offers challenges to interpretation. Indeed, the language of speculative thought, a language that defines and articulates essential features of Geist, invites one to take a very lofty and holistic perspective on human existence. Beyond the difficulties due to his convoluted style, his peculiar use of terms, and the absence of explicit definitions prior to referring to essential concepts, there is also a tendency for Hegel to move between speculative and historical discourse without signaling the shifts between levels. Lack of clarity about whether the principles Hegel presents fall on the speculative or on the historical level can result in charges of mystification, most notably by thinkers such as Karl Marx in his early 1840's writings. In this essay I attempt to clarify the concept of Geist by: 1. defining the speculative transcendental meaning of Geist, which will involve articulating the principles that structure Geist's essential features, especially as presented in Hegel's Logic; 2. explicating the historical and existential dimension of Geist, which will focus on the nature of its action and embodiment, specifically attending to the nation state as the true historical individual; and 3. explaining the 
essential connection between the speculative and the historical in such a way as to address their dialectical unity in difference, thus alleviating the problem of Geist's temporality being merely discounted by ontology.

When considering Geist from the perspective of both its speculative principles of explanation and its concrete historical actualization, and in taking Geist as the connecting link between logic and history, important questions need to be addressed. What sort of determinate being does Geist have? What is the specific nature of its mediating function in history? Is there an overriding teleology involved in the self-determination that Geist exhibits historically? These fundamental questions will guide this essay's explication of the role of Geist in Hegel's philosophy.

\section{I.}

We begin with a discussion of how Hegel's speculative principles of explanation apply to the concept of Geist. Geist is the active expression of the Absolute Idea (the total conception of what is) in world history. Moreover, Geist is the conceptual link between logic and history in Hegel because it is the actual mediation of subject and object, the overcoming of dualities, and the actualization of Absolute Reason in the historical process. As such, Geist must be understood as combining the "infinitude" of speculative thought, the inner self-reflexiveness of the dynamic of subject and object, with the finitude of temporal movement in space and time, where reflexivity is conditioned by external contingency. Clarifying the link is important, for the Absolute Idea is a meta-principle of explanation which in itself can be no substitute for actual reality. While the Idea provides the principle of the intelligibility of what is, it cannot subsist in some sort of static perfection all its own. Speculative principles lack actuality (Wirklichkeit) without concrete embodiment or expression, in 
contrast to Platonic Forms that allegedly have independent subsistence. ${ }^{2}$ Furthermore, because the Absolute Idea must presuppose concrete existence, the relation between Idea and existence cannot be conceived in terms of the traditional reality/appearance distinction; rather, the internal opposition within this distinction collapses in Geist as the unity of subject and object, a unity in difference that expresses the absolute intelligibility of the totality of historical life.

The question of Geist's determinate being first must be approached by referring to the conceptual structure of individuality as it is presented in Hegel's Logic. The driving theme of the last division of the Logic entitled the "Doctrine of the Concept" is the "syllogistic" relationship between the concepts of universality, particularity and individuality (Hegel, Logic, pars. 163, 181 [add.], 198). In this context, individuality is likened to the conclusion of a syllogism in which universality is the major premise and particularity the minor premise. Just as the conclusion of a syllogism is arrived at through the mediation of its premises, so individuality is a mediated synthesis of universality and particularity. In the case of individuality, however, the concern is not with formal deduction because the mediation involves the production of a content within a totality. Totality is to be conceived as an individual qua concrete universal, an actualization in which universality and particularity function as conceptual correlates of explanation and where both the intelligible form and determinate content of the individual are distinguishable but inseparable. Accordingly, the actual historical individual must be a subject-object that can be both intelligibly articulated and concretely experienced: articulated through principles of thought that provide the elements of form and structure, and experienced in the particularizations of time and space. Outside of their complementary connection, both the universal and the particular remain abstract and indeterminate, the former without an actual content and the latter without rational intelligibility. Underlying the Hegelism that "what is rational 
is actual and what is actual is rational" is the presumption that any explanation of a subject matter involving specification of a concrete content, e.g., historical states of affairs, events, etc., must express the dialectical structure of an articulated totality (Hegel, Right, par. 142 [add.]). This implies that historical reality itself must be a development that occurs in the three interconnected “dimensions" of universality, particularity and individuality (see Right, pars. 7, 187). ${ }^{3}$

Despite the fact that the term "Geist" connotes the idea of a "spiritual" individual, this should not lead to the inference that it is non-material in some supernatural way, like a disembodied spirit. Geist is spiritual because it is a self-consciousness, i.e., a self-related awareness that exhibits the totalizing characteristics of the Absolute Idea. Consequently, the being-for-self or principle of selfreference permeating the Logic pertains to thought thinking itself and to the totality of what is, in which the principles of thought are immanent. Self-consciousness, therefore, is not for Hegel primarily a psychological notion, despite the fact that it has a psychological dimension in the mental life of human beings, but is rather a logical or speculative conception defined in terms of the function of reflexivity, or reflection-into-self. Furthermore, reflexivity in totality is a result of applying the principle of negation to every level of thought in its attempt to posit conceptual determinations. Therefore, Geist as a concrete totality exhibits self-conscious negativity throughout its concrete manifestation, socially, politically, and culturally.

If we consider a person to be the unity of mind and body, and find that personality is expressed in one's activity, then, by parallel, Geist is more like a person or a real individual than a pure mind abstracted apart from embodiment. Accordingly, in Hegel's conception Geist does not specifically denote some sort of general consciousness or single supra-personal mind common to all thinking beings, for analogy between Geist and the individual conscious human mind breaks down 
when simply utilizing psychological criteria for identifying Geist (Solomon 657-661). On the other hand, Geist considered as a trans-historical totality (WeltGeist), as distinct from the VolkGeist or spirit of a nation, cannot be spatially or temporally located in a specific way, as can ordinary persons. Thus Geist should be understood not as we usually think of particular persons psychologically but rather as a universalizing and particularizing activity strung out over the complete course of human time and integrated into a single whole such that "the entire history of the world is to be viewed as a single "life"” (Martin, "The World Spirit" 156). "Hegel thinks of Geist as the "life" or "personality" of history because it is "infinitude as the supercession of all distinctions, the pure rotation on its own axis, itself at rest while being absolutely restless infinitude, the very self-dependence in which the differences brought out in the process are all dissolved" (Hegel, Mind 221). Hence, Geist as a living whole must constitute a circuit of activity which is self-contained, self-sufficient, which produces its own content, and is its own object—a macro-reflexive activity producing itself out of itself.

The answer to our first question about the determinate being of Geist already brings us to the second, for if Geist is fundamentally activity then we need to explore further the nature of this activity. In the first place, how does the activity of Geist produce an integration within itself? According to Hegel, the "function of mediation is an essential moment of the spirit. Its activity consists in transcending and negating its immediate existence so as to turn in again upon itself; it has therefore made itself what it is by means of its own activity" (Hegel, Lectures on History 50; 57-58). This process of mediation is a dialectical development in which oppositions internal to Geist are generated and resolved. Speculatively, the dynamics of the Aufhebung, the sublating of oppositions resulting in an identity-in-difference, are given formal exposition throughout the Logic. In shifting to Geist as an historical subject/object we must turn to the realm of what Hegel calls "Objective 
Spirit," the realm of human society and the nation-state, in order to get a fix on the concrete activity of Geist.

\section{II.}

According to Hegel, "the spirit in history is an individual which is both universal in nature and at the same time determinate: in short, it is the nation in general, and the spirit we are concerned with is the spirit of the nation ... the nations are the concepts which the spirit has formed of itself" (Lectures on History 51; 59). This means that Geist realizes its activity and its consciousness of itself in the world through the activity and self-consciousness of a nation of people (VolkGeist), the extent of this self-consciousness varying according to the level of the social, political and cultural development of the particular nation in question. The story of the development of Geist's consciousness of itself is found in the struggle for recognition and the resolution of this struggle both within and between nations. Because historically nations rise and fall, Geist as the ultimate historical totality can be identified not with any one nation in particular but rather with the historical development of nations throughout history as a whole. As Hegel puts it,

the particular spirit of a particular nation may perish; but it is a link in the chain of the world spirit's development, and this universal spirit cannot perish. The spirit of the nation is therefore universal spirit in a particular form; the world spirit transcends this particular form, but it must assume it in so far as it exists, for it takes on a particular aspect as soon as it has actual being or existence $(53 ; 60)$.

Capturing the dynamic nature of Geist's activity requires looking at what Hegel refers to as the "categories under which the historical process presents itself to thought" $(31 ; 34)$. These are the categories of change, rejuvenation and reason. 
According to Hegel, the category of change "comes from our observation of the changing individuals, nations and states which flourish for a while, capture our interest, and then disappear" $(31 ; 34)$. The negative aspect of the idea of change is manifest in the "motley confusion" of things in their transience which "moves us to sadness" when we think that "the finest manifestations of life must perish in history" $(32 ; 34)$. This transitoriness of individual life in history is not just a contingency that we happen to observe but rather is a necessity that has its foundation in the logical Idea itself, specifically in the notion of a life-process as a continual series of generators and the generated in which the living individual must exhaust its life for the sake of its kind or species (see Logic, pars. 221, 222). But the death of any individual is not the end of the matter, for in order for the species to continue there must be a reproduction of life in the form of new individuals who not only continue to procreate but who also sustain consciousness of a world, without which there can be no Geist.

Next is the historical category of rejuvenation. In history, unlike the natural world, which is for Hegel a mere repetitive cycle of birth and death, rejuvenation brings new life that becomes transformed to attain a higher level of development. In Hegel's words, "[t]he rejuvenation of the spirit is not just a return to an earlier shape; it is a purification or further elaboration of itself" (Lectures on History $33 ; 35){ }^{5}$ Thus, history produces not only renewal, but novelty as well. This novelty is manifested in Geist's taking many directions in order to enlarge its activity to meet new challenges. Despite the new forms that Geist produces in the ongoing accomplishment of its activity, this activity is still subject to the limitations that nature imposes, creating obstacles to its successful advancement. Thus, despite the rebirth and progress characteristic of rejuvenation in history, Geist's 
life-activity is perpetually frustrated and continues on in an indefinite series of unsatisfied endeavors, what Hegel would call a false or spurious infinite (Schlecht-Unendlichkeit) (see Science 138-140). ${ }^{6}$

However, it is also Hegel's claim, and indeed one of his most controversial ones, that "the final purpose of the world is accomplished no less than ever accomplishing itself”' (Logic, par. 234 [add.]). ${ }^{7}$ From the perspective of the Logic this speculative truth requires a conceptual move to the standpoint of the Absolute Idea in which an identity-in-difference is grasped between what-is and what-ought-to-be, where in the cognition of the true nature of infinite Will there is recognition that the Good, as the ultimate aim of the Will, is always executed. From the perspective of history this involves the recognition that "even when it is frustrated, it [Geist] remains true to its character as a spiritual being, a being whose end is not the finished product but the activity of production, so that it still affords the spectacle of having exhibited its active nature" (Lectures on History 33; 36).

This recognition of an ultimate end that transcends finite aims and accomplishments in history, but is nonetheless immanent to historical activity, brings us to Hegel's third category of historical thought, which is reason. According to Hegel, this category "is present in our consciousness as a belief that the world is governed by reason. Its proof is to be found in the study of world history itself, which is the image and enactment of reason" $(33 ; 36)$. In world history the connection between the rational and the empirical sides of Hegel's philosophy comes to the fore, for it is only in doing a philosophically guided historiography that the rationality of the historical process can be given confirmation. The logical Idea itself articulates the rationality of reality in that the Idea contains the speculative recognition that finite activity is the self-expression of a purpose that is infinite (see Findlay 8-11). In this speculative thought, contingency and irrationality are integrated into Reason through the recognition that they are, as J. N. Findlay has put it, "teleologically 
necessary for the life of reason" (11). In other words, the goal of rational activity, self-determination, requires an act of self-limitation that can be accomplished only through the utilization of the contingencies of finitude, which provide the challenges for self-transcendence. Geist in its temporal working out of history gives this principle of the Idea its concrete reality, and that reality is presented to philosophy in the examination of history. This is not to imply that the empirical examination of history can operate merely on the level of sense-perception, for it must be guided by the presupposition, which is grounded in the Idea, "that reason governs the world, and that world history is therefore a rational process" (Hegel, Lectures on History 27; 28). Thus, although history must be taken as it occurs in space and time, the contingencies associated with particular finite ends must not be confused with rational activity as the ultimate end of history. For Hegel, the speculative truths of the Logic, especially the idea that self-determination develops in the confrontation of self and other, must be one's guide to the interpretation of the life of nations and the finding of patterns and purpose in their rise and fall. This discussion of reason in history already goes some way towards answering the third of the major questions about Geist, namely the nature of its end or purpose, and this can be further elaborated.

According to Hegel, the ultimate aim of Geist is "to create a spiritual world in accordance with its own concept, to fulfil and realize its own true nature, and to produce religion and the state in such a way that it will conform to its own concept and be truly itself or become its own Idea" (53; 61). When Geist accomplishes this aim it also attains knowledge of itself as freedom, i.e., as self-sufficient and self-determining according to its infinite negativity. This means that Geist becomes aware of itself as the power of overcoming all of the oppositions that are produced within itself and of transforming them into higher unities. This realization is attained in the actualization of 
freedom in the nation-state where the oppositions that obtain in the human struggle for recognition are optimally resolved. Thus, Geist's achievement is attained in and through human society, through rational freedom and the self-consciousness of this freedom. History as a rational development is manifested both in the progressive actualization of freedom, especially in social and political life, and the self-consciousness of freedom, articulated in the art, religion, and philosophy (the Absolute Spirit) of an epoch.

What has been emphasized thus far is that for Hegel the historicity of Geist is just as necessary to its being or existence as the logical Idea; these two distinct dimensions of conceptualization, the speculative and the historical, are not only compatible but necessarily connected. Indeed, we may put it in Hegelian language by saying that in Geist these levels form an identity-in-difference in which distinct forms of discourse point to the same basic content. Thus, the importance of empirical history for Hegel cannot be under emphasized, for without history and real progress in its movement there could be no reality for the Absolute Idea. As Hegel said it, "in isolation, the inward dimension of the Idea would remain a lifeless abstraction, and it is only by means of activity that it acquires real existence" $(79 ; 93)$. Through human activity in human history the logical Idea is given actuality, and Geist constitutes such an actualization by providing the necessary self-expression of freedom and reason in the totality of the life of nations. The freedom and reason conceptually contained in the Idea is demonstrated through both history and philosophyin the progress that history makes towards the perfection of human activity and in the self-consciousness of this achievement, which is provided in the rational recapitulation of historical progress in the philosophy of history. 


\section{III.}

At this point we can explore more directly the exact connection between the speculative and the historical in Hegel. We have considered Geist to be the active expression of the Absolute Idea, which is the ultimate speculative principle of intelligibility, and that Geist is fundamentally historical in nature. Superficially this could suggest that history is simply a repetitious working out in time of what has already been developed in the Logic. While Hegel did appear to believe that the history of philosophy has proceeded along lines parallel to the conceptual development of the categories of the Logic, and that his own philosophy completes this development with the explication of the Absolute Idea, nonetheless the history of philosophy is not the same as world history, and philosophy is no substitute for the concrete development of freedom and reason in world historical events and actions. Philosophy, as the science of the concept of the Absolute, the totality of what is, participates in what Hegel calls “Absolute Spirit," which means that this science affords special insight into the universal function of Reason (see Hegel, History, Vol. 1, Introduction). However, the actuality of Reason requires a temporal development that contains particularity, contingency, and irrationality. We might say, metaphorically, that Reason in history is necessarily weighted down with the burden of finitude and all its exigencies (in contrast to Plato where the weighting down of reason by the non-rational is contingent and temporary). Finitude constitutes a realm of external limitation that must be taken up and utilized in order for there to be any actual expression or manifestation of rationality. The temporal process of movement and change is the vehicle through which principles of rationality emerge into self-consciousness, where through concrete human effort the real becomes rational, i.e., intelligible. 
Understanding how for Hegel Reason attains expression in history requires a sharp distinction (though not a complete separation) between logical and temporal development. Failure to make such a distinction can lead to maneuvers similar to the one Friedrich Engels made when he converted the conceptual transition from quantity to quality in Hegel's Logic into a paradigm for understanding historical transitions. More recently, Stanley Rosen has held that in Hegel the process of human history "reveals the eternal and absolute process in a series of stages that are temporal analogues to the stages of the eternal process" (G. W. F. Hegel 39). This tendency to temporalize logical or speculative categories into concrete historical ones leads to a logicization of history, which is, in a way, the reverse of the mistake made by traditional metaphysics. Traditional metaphysics mischaracterizes the nature of the Absolute by treating it as a kind of thing or entity, thus subordinating it to the logic of the finite understanding (Verstand). On the other hand, the logicizing of temporal development takes the finite and treats it as if it were of an infinite or speculative nature, thus trivializing the role of contingency and accident in history. In both cases the mistake is to confuse two distinct levels of discourse: discourse about principles of intelligibility and discourse about that to which those principles apply in the concrete empirical world. Although each type of discourse is connected to the other, for each there is a subject matter that must have its own proper explication. We should accordingly delineate in Hegel the distinction between logical or speculative development and actual historical development with greater precision.

In a development that is speculative the subject matter consists of pure thought determinations or principles of intelligibility viewed from the perspective of absolute self-reflexivity. This means that in the process of explicating logical concepts thought provides an explication of itself, and hence gives a meta-theoretical account of itself, an explanation of what it is to provide an 
explanation. The Logic is a conceptual system in which thought can reflect into itself in progressively higher or more enriched stages until it finally grasps its own essential nature fully as Absolute Idea. The Absolute Idea can be considered as the ultimate organizing concept of the system under which all the other concepts are arranged in a graded "scale of forms." An organizing concept is best understood with reference to the "subordinate/superordinate" ordering which occurs in such a scale, where each subordinate concept contains a provisional characterization of the superordinate concept. Despite a surface appearance of linear progression in the succession of concepts in this scale, it is rather a "scale of overlapping forms" where each succeeding concept is superimposed on the previous one such that the result is a single unified and increasingly determinate totality (Martin, "Collingwood" 227-240). If we view this process of conceptual enrichment as the process of thought thinking itself, of explaining to itself the nature of its function, then we can readily see why it is an inherently circular process. The circularity consists in the fact that despite the progressive enrichment of content through the successive mediation of concepts, each stage is also a return to the beginning, i.e., at every stage the concept of totality, with which thought began, is the thematic consideration. The process begins with an abstract or immediate conception of totality and continues on to systematically generate concreteness in this content until the method of development has run its course in a fully adequate conception of totality, of the all-embracing whole. Hegel refers to the culmination of the system of logic as a "restoration of the first immediacy in which it began," the "restoration" involving a qualitative reconstruction attained through conceptual transformation rather than a simple return to the beginning (Science 840). ${ }^{8}$ As Hegel puts it,

each new stage of forthgoing, that is, of further determination, is also a withdrawal inwards, and the greater extension is equally a higher intensity ... it is in this manner that each step of the advance in the process of further determination, while getting further away from the indeterminate beginning is also getting back nearer to it, and that therefore, what at first sight 
may appear to be different, the retrogressive grounding of the beginning, and the progressive further determining of it, coincide and are the same (840-841). ${ }^{9}$

Thus, according to Hegel, the science of logic is "a circle returning upon itself," indeed a circle which is a "circle of circles" given the reflexivity that permeates each of the logical concepts and the entire system. It is on this basis that the pinnacle of the system, the Absolute Idea, is itself Reason understood in terms of its absolute self-relation or recursiveness.

The process of history, like logical development, involves dialectical advancement, which is to say that concrete historical determinations relate to one another in oppositions that are transcended toward higher, more inclusive, more adequate determinations. However, on the other hand, the historical process is not a purely conceptual development as is the speculative, but rather involves a genetic dialectic which is rooted in temporality, in the movement from earlier to later in the linear flow of events. Whereas speculative development occurs in the complete inwardness and infinitude of pure thought such that the earlier/later distinction cannot apply, historical development takes place in the medium of time and externality, where individual actions and events are unique and non-repeatable. The distinctive temporal dimension of history lies in its going forth. While it may appear at times to have somewhat retrograde movements, due to the spiraling character of its advance, the troughs of regression are nonetheless part of an overall trajectory of advancement. While historical movement is, like the speculative, cumulative in that each stage of development preserves the essential truths of all that preceded, the transitions in history are in no sense a return to the beginning since real novelty is produced in the taking up of the limitations of finitude within Geist. This requires, as we saw previously, not only that actual change occurs but also that this change is governed by an inner principle that produces novelty comprehended in the context of an intelligible conceptual structure. This intelligibility rests upon the circumstance that history is 
purposeful, and that purposefulness is manifested at various levels in the life of individuals who in their activity self-consciously pursue purposes that are rational (O'Brien 56).

While the Logic may be thought to have a purposive aspect insofar as the Absolute Idea is the conceptual end or goal of logical development, the "teleology" here is not intentionalistic, which is to say that it does not proceed according to the striving of an individualized subjectivity. Teleological relationships involve the particularization of a universal goal, cognized as a subjective end and mediated into objectivity via the utilization of external means in practical activity. No such activity occurs in the Logic, and while speculative logic does provide an explication of the concept of Teleology as a pure thought determination, this is not the same as the actual working out of a teleological relation in a sensuous medium. When Hegel states that the realized teleological end is the explicit unity of subjectivity and objectivity he is explicating the concept of what it means to attain finite accomplishment in the concretization of universal goals; and when he claims that the Absolute Idea as the completion of the Logic is the unity of the subjective and objective he is referring to the infinite accomplishment that occurs in the speculative knowledge of thought by itself. This accomplishment is entirely conceptual and lies solely within the domain of pure thought as an eternal and infinitely circular process. For this reason, the "teleology" in the Logic is internally a-historical.

Nonetheless, philosophical History as narrative of the development of the world spirit (WeltGeist) involves a profound correlation between the infinite thought of speculative logic and thinking about the actual concrete world. The connection lies in the very character of Geist as involving, on the one hand, an activity of structuring which is self-contained, without limits or boundaries, and, on the other hand, an embodiment or medium in which externality and limitation are present. We might say that these two factors taken together constitute the preeminent dialectical 
opposition that must somehow be reconciled. One common (mis)interpretation is that for Hegel the reconciliation takes place at a particular stage in history in which historical development becomes essentially complete (see Rosen, G. W. F. Hegel 33, 45-46). ${ }^{10}$ While Hegel held that history finally becomes intelligible with his philosophy of the Absolute, in which human thought is given full conceptual accessibility to the nature of the Absolute, it is also evident that the manifestation of Absolute Spirit in the life of peoples was a task that for Hegel always remained to be accomplished (while always being accomplished) (see Hegel, Lectures on Religion 151; pt. 3, sec. 3). It does not suffice to distinguish essential from contingent history and claim that while the latter continues on in the mode of temporal change after Hegel's philosophy makes its appearance, the former is already complete in that, coincidental with the achievement of the modern nation state, Hegel's philosophy provides a complete explanation of the structure and significance of history, and hence nothing essentially new can occur. Such an essentialist perspective constitutes a speculative but not a world-historical completion. Speculative completion means only that the Absolute Idea has been conceptually comprehended as the paradigm for self-determining activity, and hence that the true goal of history is now understood to be the development of freedom. In recognizing the necessity of finitude in history, Hegel saw that "history has to do with reality, in which the universal must in any case assume a determinate form. And no limited form can establish itself permanently in face of thought or the concept ... for thought alone is inherently unlimited, and all reality is determined within it" (Lectures on History 149; 180-81).

However, if as Hegel claims "Spirit is that infinite movement [energy, activity] which never rests ... discovering itself through the work it performs; for it is through work alone that the Spirit externalizes its universal concept and attains a real existence" (133-34; 161-162), then does not 
endless progress towards a perfectibility in history constitute, in the sense of Hegel's own definition, a "bad" or "false" infinitude in which "what ought to be" is never ultimately attained or realized? Given Hegel's distinction between infinite and finite accomplishment this conclusion may at first glance seem unavoidable. In his discussion of the transition from Teleology to the Idea in the Logic, Hegel considers the implications of the established result that the Idea is the unity of the Notion (concept) and objectivity (reality). Here he acknowledges that actual things, insofar as they are finite, are not congruous with the Idea. "Finite things are finite because they do not possess the complete reality of the Notion within themselves, but require other things to complete it ... the highest to which they attain on the side of this finitude is external purposiveness" (Science 757; 456). Since finitude is characterized by temporal change in which all things undergo generation and decay, and since temporal movement is the mark of history, it would appear that in historical development there must always be some distance between concept and reality, between "what ought to be" and "what is."

Without qualification, this conclusion rests, however, on an ambiguity that resides in the conception of historical accomplishment or completion. While the Absolute Idea does indeed set up a paradigm for actualization in history, the goal or purpose of history is not the attainment of something that cannot possibly occur, namely the materialization of a pure principle of intelligibility itself. With pure principles themselves there is never a question of a gap between "what is" and "what ought to be," since in their infinitude they are absolutely rational. Surely the demand that the finite become something that it is not and cannot possibly be, i.e., absolutely infinite, is absurd. Thus, when historical development mirrors the dynamic of the Absolute Idea it does so with respect to goals that are finitely attainable, realizable within history itself, and this must be the meaning of actualization as the sublation of the finite in the infinite. Of course, if the principles of intelligibility 
do indeed apply to history then the goals they articulate and the activity leading up to them must be rational. This rationality is manifested in history as a process of self-making and, despite the fact that historical finite activity is ongoing and never reaches an ultimate finality, historical selfdetermination mirrors the infinitude of the Absolute and expresses the intelligibility of its structure. Likewise, the finitude of all things or objects does not mean they do not correspond at all to their concept, since the actuality of any object or individual requires some congruence with the Idea. Nor does it mean that historical development cannot produce individuals that exhibit an optimum of congruence with the Idea. Indeed, with the appearance of the modern nation-state in history we have, for Hegel, reached such a level of congruence that the infinitude of the Absolute Idea can be given ideal expression in the ethical life of the social and political community. Here a level of self-consciousness of freedom is attained that allows one to say, in a nonetheless equivocal fashion, that history has reached its goal and is thus complete. I say "equivocal" because any particular nation-state is a temporary phenomenon that must give way to the restlessness of Geist, for Geist is in an unending "conflict" with itself (and in a sense is its own greatest obstacle) due to its ability to negate any of its finite characteristics. As Hegel puts it somewhat metaphorically, "[t]he will of Spirit is to fulfill its own concept; but at the same time, it obscures its own vision of the concept, and is proud and full of satisfaction in this state of self-alienation" (Lectures on History 127; 152).

In distinguishing but also showing the intrinsic connection between speculative and historical development in Hegel, and in considering the achievement of the true historical individuals, that is, constitutional nation-states, we arrive at an identity-in-difference between the infinite and the finite and hence an overlap in the types of discourse that are appropriate to characterizing the nation-state. On the one hand, in mirroring the self-determination of the Absolute Idea, the actualized nation- 
state (as explicated in the Philosophy of Right) attains self-consciousness of what it is to engage in free rational activity, which is the infinite purpose of the Absolute. But the nation-state also has its particular finite ends that remain subject to the contingencies of historical development, and which in themselves must, therefore, fall short of the Idea. Thus, the infinite end of Geist is achieved not in a final completion of temporal history but in the philosophical recognition, itself historically achieved, that finite ends serve the purposiveness of Geist, indeed that they are teleologically necessary to its activity. The historical "completion" provided by the nation-state is for Hegel a milestone in an ever ongoing process of self-realization. Speculative comprehension allows for rational selfconsciousness of this achievement, but such comprehension is distinct from actual world historical achievement, which always remains an unfinished project. In this sense, there is an unending striving toward completeness that never fully arrives but which becomes increasingly self-aware as a free activity of self-making. In short, the ontological structure of Geist in history can clarify but not overcome Geist's finitude and its existential condition.

\section{Notes}

${ }^{1}$ Robert Williams ("Hegel's Concept of Geist" 1-20) indicates that there are at least three different interpretive models of Geist, the transcendental, the ontological, and the social-intersubjective interpretations. The first views Hegel's concept of Geist as derivative of Kant's transcendental ego and a product of transcendental philosophy (the view held by J.N. Findlay, Robert Solomon, Charles Taylor, and Merold Westphal), the second treats Geist as identical with some sort of ontological subject (either humanity as a collective subject or an onto-theological subject, held historically by the left and right Hegelians respectively), and the third avoids both transcendentalism and foundationalism by taking Geist to be essentially "social-intersubjective," which is Williams' position. The orientation I take in this essay is I think compatible with Williams', although the contexts are somewhat different despite significant parallels. Whereas Williams is looking at Geist primarily from the perspective of Hegel's Phenomenology of Spirit and the Philosophy of Spirit from Hegel's Encyclopedia, my approach focuses more on the relation of Hegel's Logic to his 
Philosophy of History. Also, whereas Williams takes the concept of recognition (Anerkennung) to be the focal point for explaining the intersubjectivity of Geist, I focus instead on the question of the historical embodiment of Geist in relation to speculative principles of explanation. These two approaches are complementary in emphasizing the role of temporal development in the achievement of recognition and of self-conscious freedom.

Joseph McCarney (Hegel on History, esp. ch. 3) discusses the transcendent and the immanent reading of Hegel on history and holds that "the balance of argument, of considerations capable of determining an unbiased intellect, favours the immanent view" (41). My discussion of the speculative and the historical in Hegel does not address this issue head-on but suggests that the answer is perhaps more complicated and must be assessed dialectically.

2 "[S]pirit is preceded not only by the logical Idea but also by external nature. For the cognition already contained in the simply logical Idea is not cognition for itself, but merely the Notion of cognition thought by us; it is not actual spirit, but merely the possibility of it. In the science of spirit we have only actual spirit as our general object, which has nature as its proximate and the logical Idea as its primary presupposition" (Hegel, Philosophy of Subjective Spirit 27).

${ }^{3}$ See also Hegel's Lectures on the Philosophy of World History 30, 76f; Die Vernunft in der Geschichte, 32-33, 90f. (Hereafter Lectures on History; Geschichte for the English and German with respective page numbers.) The Doctrine of the Notion (Begriff) is perhaps the most relevant section of the Logic to social and political theory, as well as to the philosophy of history, due to its focus on the various dynamics of development. This section is subdivided into three parts: the subjective notion, the objective notion, and the idea which articulates the unity of subjective and objective. The first part, the subjective notion, contains three "moments" or functional parts: universality, particularity, and individuality (pars. 163f). The transition in the Logic from universality to particularity to individuality (or concrete universality) is expressed in the social and political context in the conceptual transition from Abstract Right to Morality to Ethical Life. Thus, the nation state is internally integrated into a true individual by means of this "syllogistic" dynamic. In history at large, "[t]he universal Idea attains phenomenal reality in the state," and hence the state is a "spiritual individual"(Lectures on History 96).

${ }^{4}$ Also, according to Martin, "Hegel's model for Spirit is obviously the individual person or self" (155). However, we should note two important differences between Geist and ordinary persons: 1. the human person is usually considered to be distinct from the results of his or her activity whereas Geist is not; 2. human persons are finite beings whereas Geist is infinite. Insofar as human individuals exemplify or approximate the logical conception of individuality it is not a mistake to conceive of Geist on the model of the human person, as long as we remember that the latter is an imperfect expression of an ideal-type which is most perfectly manifested in Geist as a whole. 
${ }^{5}$ See 60-61; 69-71, also 63; 73 where Hegel says: "Each new individual national spirit represents a new stage in the conquering march of the world spirit as it wins its way to consciousness and freedom. The death of a national spirit is a transition to new life, but not as in nature, where the death of one individual gives life to another individual of the same kind. On the contrary, world spirit progresses from lower determinations to higher principles and concepts of its own nature, to more fully developed expressions of its Idea."

${ }^{6}$ See also Hegel's Logic, par. 94. In Hegel's discussion of Infinity under the category of Determinate Being (in both the Encyclopedia Logic and the Science of Logic) the idea of a "spurious" or false infinite refers to an unending series which is really just the finite in a progression to infinity, a mere negative infinity, the infinite of the understanding (Verstand). In the context of the conceptual transition from the category of Life to the categories of Cognition and Volition, the finite will attempts a realization of the world-as-it-ought-to-be on the basis of the finite cognition of the worldas-it-is, but this attempt remains a mere "ought." The universal Mind-Will of the human world generates culture and civilization which progresses forward, but in an infinite series of endeavors which seemingly never adequately accomplish the ultimate Good. This is resolved, however, in the transition to the pinnacle of the Logic, the Absolute Idea. See Logic, par. 234.

${ }^{7}$ See par. 212 (add.); Lectures on History 66-67; 76-78.

${ }^{8}$ Hegel, Science of Logic 840; Wissenschaft der Logik 569. (Hereafter Science; Wissenschaft for the English and German with respective page numbers.)

${ }^{9}$ Michael Kosok says, "Dialectics is not either a triad-linearization or a self-enclosed synthesis of opposites-it is rather expressed through the cyclic nature of self-return through self-espansion ... Methodologically this means that one cannot view the non-linear logic of this dynamics as a linear progression or even a progression along a circle from an imperfect abstract immediacy to a fully developed immediacy if one does not see that the end-state of total self-mediation is but the conditioned [sic.] for the very appearance of the 'first immediacy and universality.' All movement is internal self-expansion of a singular immediacy in a dynamic of its self-reflectivity: there is no End or Beginning immediacy identifiable as such" (The Dialectical Matrix" 129-130).

${ }^{10}$ Elsewhere Rosen remarks that "[s]ince logic is the truth of history, or conversely, since history is the manifestation of the Absolute in human time (that is, the humanly accessible meaning of the logical identity-within-difference of eternity and temporality), if history were not essentially complete, the truth of logic would be inaccessible" ("Hegel and Historicism" 39). See also page 41 where Rosen distinguishes "essential" from "contingent" history such that with Hegel's philosophy essential history is complete, meaning that "nothing essentially new can occur. And this, again, means that all categories of logic are manifest." 


\section{Works Cited}

Findlay, J. N. "Hegel's Use of Teleology." The Monist 48, no. 1 (Jan. 1964): 1-14.

Hegel, G. W. F. Die Vernunft in der Geschichte. Hrsg. Johannes Hoffmeister. Hamburg: Felix Meiner, 1955.

—. Hegel's Logic. Trans. William Wallace. Oxford: Oxford University Press, 1975.

-. History of Philosophy. Trans. E. S. Haldane and F. H. Simson. London: Kegan Paul, Trench, Treubner Co. Ltd., 1896.

-. Lectures on the Philosophy of Religion. Volume 3. Trans. Speirs Sanderson. London: Routledge Kegan Paul, 1962.

—. Lectures on the Philosophy of World History. Trans. H. B. Nisbet. Cambridge: Cambridge University Press, 1975.

—. Phenomenology of Mind. Trans. J. B. Baillie. New York: Harper Row, 1967.

—. Philosophy of Right. Trans. T. M. Knox. London: Oxford University Press, 1978.

—. Philosophy of Subjective Spirit. Ed. and trans. M. J. Petry. Boston: D. Reidel Pub. Co., 1979.

—. Science of Logic. Trans. A. V. Miller. London: George Allen \& Unwin, Ltd., 1969.

—. Wissenschaft der Logik. Hrsg. Georg Lasson. Hamburg: Felix Meiner, 1966.

Kosok, Michael. "The Dialectical Matrix or Hegel's Absolute Idea as Pure Method." Hegel-Studien Beiheft 18: 115-137.

McCarney, Joseph. Hegel on History. Routledge Philosophy Guidebooks. London and New York: Routledge, 2000.

Martin, Rex. “Collingwood's Essay On Philosophical Method.” Idealistic Studies 4, no. 3 (Sept. 1974): 224-250.

—. "The World Spirit." Southwestern Journal of Philosophy 2 (Spring/Summer 1971): 153-161.

O’Brien, G. Dennis. Hegel On Reason In History. Chicago: The Univ. of Chicago Press, 1975.

Rosen, Stanley. G. W. F. Hegel: An Introduction to the Science of Wisdom. New Haven: Yale Univ. Press, 1974. 
—. "Hegel and Historicism." Clio 7, no. 1 (1977): 33-51.

Solomon, Robert C. "Hegel's Concept of 'Geist."” Journal of Philosophy 65, no. 21 (1968): 642661. Reprinted in Robert C. Solomon, From Hegel to Existentialism. New York and Oxford: Oxford University Press, 1987. 3-17.

Williams, Robert R. "Hegel's Concept of Geist." Hegel's Philosophy of Spirit. Edited by Peter G. Stillman. Albany, NY: SUNY Press, 1987. 1-20. Commentary by Richard Dien Winfield. 21-24. 